\title{
On Logic and Moral Voice
}

\author{
DEBORAH ORR Toronto, Ontario
}

Keywords: Wittgenstein; Gilligan; logic; epistemology; gender; ethics; moral reasoning; moral voice; moral talk.

\begin{abstract}
This paper explores some aspects of the concept 'logic' and its relation to moral voice, and argues that Menssen uses it too narrowly in her respone to Orr's "Just the Facts. Ma'am" and the work of Carol Gilligan. Grounded in the work of the later Wittgenstein, it is argued that formalized logic misses much of natural logic; the concept of 'moral talk' is developed to theorize Gilligan's ethic of care; it is argued that this form of moral deliberation is not argumentation in the formal sense; and the relationship between logic and epistemology is explored through the consideration of moral talk as a language-game which is woven into gendered forms of life. Finally, it is argued that the notion of a universal logic is the product of an oppressive patriarchal culture and should not be defended by feminists.
\end{abstract}

"The Master's Tools Will Never Dismantle the Master"s House" Audre Lorde. Sister Outsider

In this paper I explore some aspects of the concept 'logic' and especially its relation to moral voice. My position is that this term is often defined too narrowly, in ways which are misleading, oppressive, and even anti-human. This, I maintain, is the problem with the definition of logic employed by Menssen, who narrows it to denote what she believes to be a 'universal logic', in her response to my paper "Just the Facts, Ma'am"' and to the work of Carol Gilligan and her colleagues". I draw heavily on the work of the later Wittgenstein to argue that there is much in the natural language concept of logic, and much that we call logic in practice, which formal, and many informal, theories of logic miss. Logic. Wittgenstein shows, is a family resemblance concept; like "game't it is a word in our natural language with a range of uses. This range is related by numerous similarities and overlaps, but within that range two uses may share little or nothing, although they are related through intermediate cases. Some of what is a part of natural logic(s) but is missed by the games of formalized logic can be discerned through an examination of what 1 call, in an appropriation of Sheila Mullett's term, 'moral talk', one example of which is displayed in the now famous snippets of Amy's response to the Heinz dilemma. In this connection the second major point of my paper is that moral talk, while it is certainly a form of moral reasoning which displays a logic of its own, is not a form of argumentation in Menssen's traditional sense, a moral argument which is logically valid." I will explore the connection of 'logic' with epistemology through the consideration of moral talk as a language-game which is woven into gendered forms of life. This language-game is not confined to females or feminine 
forms of life ${ }^{7}$ but, in important respects, is rooted in primitive and universal aspects of all human life, most especially human relatedness. Based on this discussion I will schematize the main features of the logic of moral talk as it is employed by Amy in her practice of ethical caring. Finally, I argue that the notion of a universal logic is the product of an oppressive patriarchal culture and thus should not be supported by feminists. Of course, given space limitations, the extensive undertaking I have outlined will be more schematic than fully developed and many issues will be ignored entirely, especially the important question of how the care and the justice moral paradigms might be related in an ethic of convergence ${ }^{x}$.

In the paper whose title is my epigram, Audre Lorde exposes narrow and exclusionary definitions as oppressive, and, when used by feminists, as not only oppressive of other women but also supportive of patriarchy. If even as potentially revolutionary a term as 'feminism' may conceal a patriarchal bias, then surely such core concepts of contemporary western culture as 'logic', 'thinking' and 'rationality' call for critical scrutiny, "For", as Lorde has warned,

the master's tools will never dismantle the master's house. They may allow us temporarily to beat him at his own game, but they will never enable us to bring about genuine change. And this fact is only threatening to those women who still define the master's house as their only source of support. [emphasis in original]"

In Words of Power, her study of the history of logic, Andrea Nye addresses the question of how a feminist might best respond to dominant culture logics. In a Wittgensteinian spirit which locates speech in human activity, she argues that, "All human communication, including logic, is motivated"," and consequently she devotes her study to uncovering the self-interested motives. which lie behind the classics of the logic canon. But her argument against what Alison Jaggar has called "The Myth of Dispassionate Investigation"" , a variety of "the view from nowhere', leads her to the position that there "can be no superior logic that will show up the mistakes of logicians; there can be no feminist logic that exposes masculine logic as sexist or authoritarian." 12 While I agree with Nye's critique of masculinist logic as well as one aspect of her conclusion regarding a 'superior' logic, i.e. that what Wittgenstein called a crystal logic underpinning thought $t^{1.3}$ is an illusion, I do not think that it follows that there can be no superior logic in the sense of a logic better suited to advance a feminist liberatory project. For instance, Alison Jaggar has argued from a socialist feminist position that women (and other oppressed groups) are in an historically advantaged epistemological position $^{14}$, and thus we might expect a superior, that is, potentially more liberatory, $\operatorname{logic}(s)$ to emerge from these groups. I tend to agree with the implications of Jaggar's position rather than Nye's regarding a "superior" logic but I will not argue this here, nor will I argue from precisely her political position. Rather, my argument, which is consistent with Jaggar's, is that natural language practice can provide us with all we need by way of an alternative to patriarchal formal logic games $^{15}$. In this both Jaggar and I agree with Andrea Nye who, refusing to enter into the formal logic games on their own terms, has said that. 
If logic is words of power that proclaim an authoritative unitary truth, there is another power in words, the power to respond and so to challenge another's discourse and refuse it pretensions to autonomy. The antidote to logic is no supra-logical metalanguage that will criticize and regulate the forms of logical thought, but language itself, the normality of human interchange that logic refuses... ${ }^{16}$

Thus I hold that if we wish to understand the logic of moral reasoning, then we could profitably listen to "language itself", in all of its diversity, instead of looking only at what the universal logic wants to show us.

The wide-spread sense among feminist scholars that the tools of liberal patriarchy are inadequate to the tasks of describing the logic of the moral practice of many women and members of other marginalized groups, or of developing adequate theory for a truly feminist ethic, is well expressed by Susan Parsons:

Feminist writings, by contributing to the present criticisms of moral epistemology, have left in their wake a great number of issues which now call for some imaginative and sensitive handling if we are to develop in our understanding of the moral enterprise. We need to consider an account which is not only more satisfactory in its understanding of feminist concerns, but also more adequate as a rendering of the logic of moral reasoning, for these two are inextricably bound up with one another. ${ }^{17}$

This statement concerning "the logic of moral reasoning" appears in an article with the title, "Feminism and the Logic of Morality: A Consideration of Alternatives"18. In it Parsons explores the "logics" of the styles of moral thinking prescribed by liberalism, naturalism, and social constructionism. In her use she does not mean 'logic' in Menssen's universal logic sense, but logic in a sense close to the Wittgensteinian one which I use in this paper. It includes a description of thought patterns, as well as a description of how they relate to the concepts of gender and of human nature, as well as the understanding of the relevant social/historical circumstances described by each of these ideologies. Interestingly, Parsons credits Gilligan with "begin[ning] to undermine some fundamental assumptions about what the logic of morality is" by making reference to Gilligan's self-understanding of her project as "rejecting "the Greek ideal of knowledge as a correspondence between mind and form', in favour of 'the Biblical conception of knowing as a process of human relationship" "2." One of the things Gilligan's shift of focus highlights is the essential role in our moral lives of our understanding of others, although this is a form of understanding which is distinctly different from that proposed by traditional epistemology with its "problem of other minds". As I have indicated, I will approach this issue from a Wittgensteinian perspective and I propose to begin with some reminders of the understanding of logic developed in his later work.

In exploring the family of logics Wittgenstein named our tendency to sublime logic, and diagnosed some of the causes of this disease:

Why do we say a proposition is something remarkable: On the one hand, because of the enormous importance attaching to it .... On the other hand this, 
together with a misunderstanding of the logic of language, seduces us into thinking that something extraordinary, something unique, must be achieved by propositions... ${ }^{21}$

We are under the illusion that 'propositions', 'language', 'thought', 'the world' are mere clothing of a super-hard, crystal pure, underlying reality, in other words, the universal $\operatorname{logic}^{22}$, a sort of super skeleton of reality and thought. "Whereas, of course, if the words 'language', 'experience', 'world' [and 'logic'], have a use, it must be as humble a one as that of the words 'table', 'lamp', 'door'." ${ }^{23}$ In holding that "logic" is a family resemblance concept Wittgenstein was able to uncover its wide range of uses; it does not only denote the universal logic, in fact, this formalized game is parasitic on our everyday logical practices. Thus, if we wish to understand logic, then we must attend to that full range: If we insist upon picking out one use as The Use then we mislead ourselves.

To understand what logic is we need to look at the sorts of things people call speaking, thinking, deciding, inferring. Wittgenstein has given us a useful because common-place example of inference: "The stove is smoking, so the chimney is out of order again'. (And that is how this conclusion is drawn! Not like this: "The stove is smoking, and whenever the stove smokes the chimney is out of order; and so ...')"'n-4. The universal logic needs the 'reconstruction' with its 'suppressed premise' but we everyday reasoners do not. This does not mean that there is something wrong with the way we reason, but rather that the universal logic does not accurately reflect our practice. Wittgenstein's use of examples such as this one was meant to persuade us to begin to attend to the full range of human practices in our quest to understand logic. This is my aim as well.

The traditional distinction between 'logic' and 'rhetoric' (I construe this later rubric broadly to include much ordinary language discourse) has served the universal logic well. It is impossible for ordinary language to object that what it does is reasoning, and that there is a logic there as well, if the universal logic has usurped the prerogative of defining these terms. This distinction obscures and mystifies the hegemony of the universal logic as a master's discourse. Further, as long as the universal logic is seen as something "sublime", its political agenda cannot be revealed or critiqued. I want to work toward that uncovering and critique by way of some remarks about epistemology and 'models of knowledge'.

Here Wittgenstein can help us again with his understanding of language as a vast complex of games connected in various ways with human forms of life. 1 have argued elsewhere ${ }^{25}$ that 'form of life' is itself a family resemblance concept for Wittgenstein which can include reference to primitive and prelinguistic facts of human life as well as the developments of our natural and social histories. Gender socialization is a pivotal dimension in the history of people in modern western culture. But thinking about gender can be simplistically two-dimensional: masculinity and femininity as popularly portrayed in the myth of white, middle-class, heterosexual, nuclear-family, suburban, North American culture of about the 1950's. But we all know by now that not even Doris Day and Rock Hudson were really like that; we need a much more complex picture of gender, as 
some of Gilligan's critics have pointed out ${ }^{26}$. In addition to this expansion of Gilligan's model, it has been argued that we must admit the possibility of many more than two moral voices ${ }^{27}$.

Gilligan has maintained from the opening pages of In A Different Voice that the two moral voices she hears are distinguished by "theme" and not by "gender" Although there is an empirical "association" of these "modes of thinking" (also called 'logics' by Gilligan) with "male and female voices in psychological and literary texts and in the data of [her] research" ${ }^{24}$ she disclaims any generalizations about either "sex" ${ }^{\text {"3n }}$ in what is to follow in her book. In her work she is clearly making a distinction between logic (moral voice/ theme/ mode of thinking) and sex (biological maleness or femaleness) on the one hand, and gender (socially constructed masculinity or femininity) on the other, although her critics often conflate sex and gender.

Although for many purposes Gilligan's simple, dualistic model of gender would need much refinement, even in this crude form it can provide the useful service to logic of helping to display some of the fundamental distinctions and assumptions which both help shore up the universal logic and undergird this culture. Important here is the association of sex with the conceptual dichotomization of emotion and reason. Each pole of this dichotomy carries in its wake a host of other mutually exclusive, hierarchical organizational categories which structure modern western culture and language: feminine/masculine; rhetoric/logic; nature/ culture; communal/agentic; community/ego; subordinate/dominant; to name a few. ${ }^{31}$ To the extent that girl children are socialized to be feminine (and I suggest that is to a great extent in this culture although I will not attempt to defend this assertion here), they are aligned with the left-hand side of each of these dichotomies; there is a parallel process of alignment of boys with the right.

By saying that they are "aligned" I mean two things: that they are seen by others and by culture generally as being associated with (or "closer to" ${ }^{\text {"32 }}$ ) "their" side of the dichotomy, and that they come to experience themselves and behave in ways that reflect that alignment. For instance, girls, because they are associated with the communal, usually develop better interpersonal skills and more affective personal relationships. As I understand her, Gilligan's theory that gender is a social construct assumes that, aside from anatomy, of boys and girls, the potential for development is more alike than different. ${ }^{33}$ That is the reason that Gilligan's starkly drawn gender stereotypes are such a poor fit for most of us, why there seems to be so much 'gender-bending', why Gilligan's "ethic of convergence ${ }^{34}$ is empirically discernable; we do not fit naturally or easily into these categories and, in psychoanalytic terms, the repressed (those parts of our selves which we have had to deny in order to at least approximate to social ideals) continually seeks to return.

So, if we think of genders, crude though our drawing of them is here, as Wittgensteinian 'forms of life', if we recognize that the sexes are differentially engendered in this culture, and if we recognize, following Wittgenstein, that 
different language-games (what Gilligan called different moral voices), and thus different logics, are woven into different forms of life, then it will make eminent sense to explore the relationships which obtain between epistemology and logic. This is because our patterns of thinking are informed by, indeed are only possible in relation to, our ways of knowing others, or, more correctly speaking, our ways of understanding and relating to others, and these in turn are a function of gender socialization.

In her use of Chodorow's object relations theory of pre-oedipal development as well as in her discussion throughout In A Different Voice, Gilligan employs a conception of femininity (feminine form of life) which is founded on interconnectedness with others. In contrast, the development of masculinity in boys (masculine form of life) calls for a development of separation from others, for isolation and even alienation. This psychological alienation is reflected, for instance, in the role of non-interference in the theories of justice ethics. As well, the cultural necessity for boys to form what Chodorow calls a positional identity ${ }^{35}$ taken together with their socialization to hierarchical, rule governed activities ${ }^{36}$ results in patterns of thinking which seek abstract, foundational principles which can 'logically' justify action.

Seyla Benhabib has developed a philosophical critique of the role of the "generalized other" in justice ethics, showing that this concept renders the practice of this ethical paradigm logically impossible because it results in the logical impossibility of distinguishing between oneself and others ${ }^{37}$. This theory is both psychologically and philosophically solipsistic. Her arguments parallel in many respects the extended treatment by Wittgenstein of "the problem of other minds' and its resultant solipsism ${ }^{38}$. His work has shown that the very possibility of any language use, and thus of moral deliberation, rests on natural, prelinguistic relatedness and responsiveness to "concrete others". This is a picture of human beings much more in keeping with Gilligan's concept of femininity with its communal ego style ${ }^{39}$ than with the isolated, alienated, and solipsistic ego of masculinity: The agentic ego of masculinity collapses into an identity with the generalized other which precludes moral deliberation and action altogether. I wish to stress that it is the understanding of humans as relational beings which is sacrificed by the universal logic and this sacrifice becomes apparent when the theories of the justice ethics, with their various conceptions of the moral agent as an 'isolated social atom', are examined.

The feminist Wittgensteinian approach I am developing calls for a radical loosening up of a lot of the key concepts of the universal logic, including 'logic', 'thinking", 'rationality", and others, and challenges the conceptual gerrymandering of traditional disciplines. It also challenges founding myths of the patriarchal order, including The Myth of Dispassionate Investigation identified by Alison Jaggar $^{40}$. This is the ideological stance of justice ethics and a founding myth of positivism, the epistemological tradition into which Jake's construction of moral dilemmas as being "like math problems with humans" fits most comfortably. We can see this fit if we remember that in the positivist tradition, "Emotions are 
allowed [to suggest hypotheses] because the so-called logic of discovery sets no limits on the idiosyncratic methods that investigators may use for generating hypotheses." ${ }^{" 41}$ But having made their limited contribution on this level, emotions not only have no role to play, they must be excised if they are not to contaminate proceedings.

When hypotheses are to be tested ... positivist epistemology imposes the much stricter logic of justification. The core of this logic is replicability, a criterion believed capable of eliminating or cancelling out what are conceptualized as emotional as well as evaluative biases on the part of individual investigators. The conclusions of western science thus are presumed "objective", precisely in the sense that they are uncontaminated by the supposedly "subjective" values and emotions that might bias individual investigators. ${ }^{42}$

In this spirit Jake declares math to be "the only thing that is totally logical" and a moral dilemma as "like a math problem with humans"43. Like the conclusions of positivist science, the conclusions of the arguments of justice ethics are to be replicable. And we do not need to be reminded of the range of injunctions by leading moral philosophers not to let emotions (relationships, feelings, desires, inclinations, the so called 'subjective' element) influence our moral thinking, from Kant's excision of "inclinations" tion, relationship, affiliation and the rest of the left hand side of the dichotomy has been outlawed in the practice of its disciplines by the dominate logical tradition of this culture and this, I suggest, is a reflection of the masculine form of life which is implicated in those language games.

Section I of Menssen's paper is devoted to distinguishing the various senses of 'logical' which she maintains Gilligan and others so sloppily 'juggle's and 'toss around'4'. I have pointed to a broader notion of logic than Menssen would countenance, and I have attempted to indicate the relationship between patterns of thinking and gender identity as a part of that broader conception of logic. There is an additional important point in Menssen's discussion with which I would like to take issue in order to amplify the logic of Amy's moral discourse.

When Menssen sets out to discredit Gilligan's use of "logical" in her discussion of Jake's and Amy's responses to the Heinz dilemma, she asks, "What is a logical argument?" and responds that "most logicians" would answer, "a logical argument is a valid argument". "Menssen's seemingly innocuous move, from speaking of Gilligan's use of "logical" to asking for a definition of "logical argument", contains the major error which becomes explicit in her next statement: "Since Gilligan doesn't speak of the children's responses as arguments, I'm going to recast the definition to refer to persons . .."(emphasis added) ${ }^{49}$. If Gilligan "doesn't speak of the children's responses as arguments", then why does Menssen make this move? Because a founding assumption of patriarchal normal ethics, as identified by Katherine Parson ${ }^{\text {s" }}$, is that moral reasoning is deductive argumentation. Menssen tells us that she has recast the definition of "logical argument" to refer to persons", a trivial point, while she smuggles in the crucial "recasting", of Jake's and Amy"s responses into "arguments", without comment. Once having 
made this move, the rest of her treatment appears unproblematic: she "reconstructs" the natural dialogues produced by Jake and Amy by "introducing some plausible assumptions" ${ }^{152}$ and proceeds to lay the results of these operations out in neatly numbered premises. These procrustean measures produce a script on the page recognizable to the universal logic but far removed from the original thought processes they purport to portray.

Menssen charges Kohlberg with "stupidity" in rating Jake's response a stage higher than Amy's $\mathrm{s}^{34}$, and she maintains that their interviewer was "unintelligent"ss in their interviews. But these ad hominem charges are unhelpful in understanding either Kohlberg's and the interviewer's assessments or Menssen's own. Gilligan herself was much more to the point when she said that,

In the interviewer's failure to imagine a response not dreamt of in Kohiberg's moral philosophy lies the failure to hear Amy's question and to see the logic in her response, to discern that what appears, from one perspective, to be an evasion of the dilemma signifies in other terms a recognition of the problem and a search for a more adequate solution. ${ }^{56}$

To recast Gilligan's point in the more philosophical terminology 1 have been using, Kohlberg, the interviewer, and Menssen herself are deafened by a moral paradigm which fails to capture the logic of Amy's moral thinking. Rather than employing the deductive logic of patriarchal normal morality, Amy was attempting to engage in something approximating Sheila Mullett's notion of "moral talk" ", but her attempt was squelched due to the interviewer's lack of responsiveness, a lack which 1 attribute to paradigm incommensurability. In what follows I draw upon Mullett's notion of moral talk but rework it in some significant ways, especially through connecting it with a Wittgensteinian understanding of logic which recognizes genders as forms of life into which moral language games are woven.

Gilligan, a developmental psychologist, does not attempt to cast her discussion of the ethic of care as a moral paradigm in philosophical terminology, although she provides us with many clues as to the shape of this paradigm. Useful here is the following statement whose context is a discussion of the developmental sequence of the ethic of care:

... just as the conventions that shape women's moral judgment differ from those that apply to men, so also women's definition of the moral domain diverges from that derived from studies of men. Women's construction of the moral problem as a problem of care and responsibility in relationships rather than as one of rights and rules ties the development of their moral thinking to changes in their understanding of responsibility and relationships, just as the conception of morality as justice ties development to the logic of equality and reciprocity. Thus the logic underlying an ethic of care is a psychological logic of relationships, which contrasts with the formal logic of fairness that informs the justice approach. ${ }^{\text {* }}$

The justice ethic's "formal logic of fairness" is clearly what I have been calling the patriarchal normal morality paradigm hung on the frame of the 
universal logic, but the notion of the care ethic's "psychological logic of relationships"sy needs fuller philosophical elaboration. Sheila Mullett develops the concept of moral talk in order to clarify the nature of Amy's response to the Heinz dilemma. In this she does not commit the error of construing Amy's response as an argument in any formal sense of that word. For Mullett moral talk is a dialogue, it is talking with and listening to another in an attempt to develop an understanding of a moral situation, to make sense of our lives as moral, to deepen and broaden our moral understanding and experience. It is not a game perhaps best, and perhaps necessarily, played in isolation, 'like a math problem with humans'. In failing to enter into this dialogue, Amy's interviewer failed to recognize her moral paradigm. For the sake of brevity, I will reproduce the six aspects of a theory of moral talk that Mullett distinguishes and comment briefly on them as they reveal elements of the care paradigm. In doing this I take myseif to be describing the logic of this paradigm in the sense that Wittgenstein has argued that "... everything descriptive of a language-game is part of logic."

Mullett points first to "the importance of the personal and the experiential.". I would relate this point to the role that gender plays in Gilligan's work. Following Chodorow, Gilligan holds that femininity is characterized (at least in white, middle-class women) by a relational ego which values and seeks intimacy with others. I suggest that it is this orientation to relationships and intimacy which characterizes other empirically identified practitioners of forms of the care ethic as well. ${ }^{62}$. In dealing with moral issues this manifests as a concern with maintaining relationships and the well-being of self and others.

Second is "the view that much of our personal experience is "pre-reflective" or tacit, i.e., not yet fully articulated" ${ }^{\prime \prime 3}$. Amy came to the Heinz dilemma with a set of tacit beliefs about "how the situation might be structured and how she could maintain certain values (i.e. save a life by getting in touch with concerned and involved relatives)".64 In articulating and giving her example of this point Mullett refers to both "personal experience" and "tacit beliefs". I would reconcile these two terms through the use of Wittgenstein's notion of a world-picture: "The propositions describing this world-picture might be part of a kind of mythology. And their role is like that of rules of a game; and the game can be learned purely practically, without learning any explicit rules." "s The relevant part of Amy's world-picture was acquired during the course of her upbringing as a girl in this culture and took the form of particular (perhaps unarticulated) "beliefs" and attitudes about relationships, values, and dispute resolution. These function as rules in her game of moral talk..$^{66}$

Third is "The radical effect on experience of socially derived concepts" Here Mullett draws on Jean Grimshaw's argument (which, incidentally, Grimshaw developed against the notion that there is a linguistic "woman's point of view" inaccessible to men) that "experience of an event . . is always mediated by concepts and ways of understanding that event which are socially derived.. " Thus, Amy's response to the Heinz dilemma was mediated and shaped by concepts, and on a deeper level of logic, by a language-game, with a social 
genesis. Her interviewer, playing a different game with a different logic, was unable to comprehend her response.

The fourth point relates to "the importance of reflecting on these concepts so as to extend, reclaim or reject them in order to elucidate our experience and our pre-reflective understanding further" ${ }^{\prime \prime 69}$. This point relates, in one sense, more to moral theory than to moral practice, but in a broader sense it is a truly moral activity in itself in that it is a clarification and reform of our moral practice. An example of this form of reflection is to be found in the case history of Sandra ${ }^{\text {"1 }}$ who probes and redraws her concepts of abortion and murder, and her conception of morality itself, when faced with an unwanted pregnancy.

The fifth point foregrounds an ideal of most of feminist philosophy, a philosophical ideal as old as Socrates although one which has historically been little practised in academic philosophy, and that is philosophy as dialectic; "much of this reflection and explication takes place in conversation with others" "It is in conversation, in sharing and exchange with others, that one is able not only to challenge and test ideas but to explore and confirm experience. One positive outcome of this dialogue will be a broadening and deepening of our moral lives."

Finally, the sixth point backs up my claim of the moral nature of theory development in point four: "this conversation, when it concerns moral life, i.e., our capacity to become good, requires caring and commitment..." This final requirement cannot be met in a purely rational, disinterested manner; it comes out only in the fullness of a lived life. As Wittgenstein has argued, one's life shows the sense of one's concepts ${ }^{74}$, and this is a logical, not a psychological, point."

Mullett, in her elucidation of moral talk and its theory has, 1 believe, helped to exposed aspects of both the deep logic and the surface logic of an ethic of care: (1) Its deep logic is a form of life socialized to, if not specifically the feminine gender, at least to a form of what Bakan ${ }^{\text {w }}$ has called a communal ego style. (2) For a practitioner of this ethic the preservation of relationships, community, and intimacy are of fundamental value in life generally and especially in moral life. The resolution of conflict and moral dilemmas draws on the strengths of the interrelatedness of human life and seeks pathways which are cooperative and call for the active involvement of others. (3) The surface logic of moral talk is, in Gilligan's word, narrative ${ }^{77}$ rather than deductive. Narrativity allows the moral thinker to more freely and creatively envision a variety of resolutions which take into account fundamental values such as the preservation and enhancement of relationships and the avoidance of harm. Thus in this logic imagination plays a major role. The creativity of this paradigm can not even be approximated by Jake's "totally logical ... math problem with humans" is guided by deductive logic which is notoriously sterile. What Lorraine Code has said about moral theories in general is especially relevant to the theory behind Jake's approach, "moral theories close off more possibilities of discernment and action than they create. A more productive route is to claim broader scope for engaged yet thoughtful practices" "emphasis in original). (4) A final but central 
aspect of moral talk is that the process of creatively envisioning solutions is enriched by talk with others who are either involved in the moral dilemma or who are believed to be in a position to contribute advice, insight, or simply moral support. This process enables us as moral thinkers to make up our minds about what to do albeit not in a strictly deductive (or inductive) fashion. Its positive outcome will be to deepen and broaden our moral lives as well as to critique cultural norms.

If the features of the ethic of care paradigm which 1 have sketched are correct, then this is a style of moral thinking which cannot be reduced to what Menssen calls the universal logic. Gilligan and the others to whom 1 made reference in my earlier paper maintain that they have found empirical examples of this style of thinking in both moral and non-moral practice and 1 have argued here that they are, in fact, examples of that style and not covert examples of the socalled universal logic." These are often the practices of women, although Gilligan is clear from the beginning of In a Different Voice that this relationship between sex and moral voice is contingent ${ }^{31}$. She gives us examples of males using this moral paradigm, especially in her important but often over-looked Chapter 6 where she discusses a "more mature" "ethic of convergence" in which, "starting from very different points, from the different ideologies of justice and care, the men and women in the study come, in the course of becoming adult, to a greater understanding of both points of view and thus to a greater convergence in judgment." $"{ }^{82}$ An implication of this statement for logic is that a description of mature moral practice, if we accept Gilligan's position that an ethic of convergence is mature moral practice, will acknowledge and relate the logics of both deductive morality and moral talk in a new synthesis.

As a philosopher and logician I embrace Wittgenstein's position that my job is to describe the logics which we find in human practices. But as a feminist $I$ understand my role to be that of an advocate and so, to conclude, 1 wish to indicate why I believe it is important that we not only acknowledge the existence of alternative, non-dominant (moral) logics but nurture them. These reasons are grounded in the ongoing feminist deconstruction of the practice of formalized logic during the past twenty-five hundred years of western history. This practice is one which both entrenches the privilege of a ruling male elite and serves to silence not only women but also other socially marginalized peoples, including many subordinated males.

Linda Nicholson ${ }^{83}$ foregrounds the historicity of the association between gender and the social organization of work, and argues that the practice of abstract formalism, constitutive of patriarchal normal ethics in particular and of the universal logic and its applications in general, is an historical product of the public (male)/private (female) split and of the particular forms of trade which have been carried on in the public sphere. The particular type of abstract formalism with which we are concerned emerged with the development of liberalism and its dichotomous conceptual scheme (or "logic of domination" in Karen Warren's analysis ${ }^{84}$ ) which I have discussed above. Thus, there is nothing either 
'natural' or universal about this aspect, abstract formalism, of the so-call universal logic. Its particular oppressiveness, not only to women but to other marginalized groups, lies in its sexing of or otherwise apportioning human capacities, dispositions and artifacts (reason, thought, form, etc. are clustered and designated male/masculine while desire, feeling, content, etc. are clustered and designated female/feminine), and the concomitant exclusion of the subordinate pole from the discourse of the public (dominant male) sphere. This has issued, in the modern period, in the invisibility of non-dominant forms of reasoning and the silencing of alternative moral voices.

The history of this erasure and silencing has been traced by Andrea Nye who positions herself on the margins of 'logic' in her reading of its history because of her insistence on the necessity of understanding the production of this history as a function of the motives, concerns, and, yes, passions, of the men who have produced it. From the Greeks, through the medieval scholastics, to Frege, Nye shows the development of logic to be not only not a unitary and universal endeavour but the work of men concerned to establish the legitimacy and hegemony of their own (male) power.

By the time of Plato, logic had defined the public space of the city as the preserve of men ... In the place of human community was founded the segregation that logic instituted, between an illogical feminine household charged with administration of slave labor and reproduction, and a male polis with law courts, assemblies, and magistrates in which rational discourse prevailed. Logic reinforced the boundaries of that segregation. ${ }^{k 5}$

Thus the alternatives for women logicians are to become collaborators in the patriarchal order, or to resist it by a return to "language itself, the normality of human interchange that logic refuses"*6. In quoting Nye I do not mean to advocate a romanticized return to some innocent, prelapsarian state, nor does Nye, but a recognition of both the inescapable role of pre-and non-linguistic experience in our linguistic practice, as well as the degree to which our moral practice lies outside the domain of formalized logics; otherwise, "speech has become the logician's propositions." " If logic is understood univocally as the universal logic, then women who "labor to make the universality of the language of logic understood" "labour to entrench their own oppression for, in the words of Andrea Nye, "[t]he feminist logician speaks from a script in which the master always wins." "s9

\section{Notes}

'Menssen, Sandra, "Do Women and Men Use Different Logics?; A Reply to Carol Gilligan and Deborah Orr", Informal Logic, XV, 2, (Spring, 1993), p. 136.

${ }^{2}$ Orr, Deborah, "Just the Facts, Ma'am: Informal Logic, Gender and Pedagogy" Informal Logic, XI, 1, (Winter 1989), pp.1-10. 
${ }^{3}$ Gilligan, Carol, In a Different Voice (Cambridge, Mass: Harvard Univ. Press), 1982, and Carol Gilligan, Nona P. Lyons, and Trudy J. Hanmer (eds.), Making Connections: The Relational Worlds of Adolescent Girls at Emma Willard School (Cambridge: Harvard University Press), 1980.

4Wittgenstein, Ludwig, Philosophical Investigations, trans. by G.E.M. Anscombe, (Oxford: Basil Blackwell), 1968, Sec. 3.

"Mullett, Dr. Sheila, "Moral Talk", Resources for Feminist Research, 16, 3 (Sept. 1987), 3235. Also see her "Shifting Perspective: A New Approach to Ethics", in Code, Lorraine, Mullett, Sheila, \& Overall, Christine (eds.) Feminist Perspectives: Philosophical Essays on Method and Morals (Toronto: Univ. of Toronto Press), 1988, pp. 109-127.

${ }^{6}$ Menssen, Op. cit., p. 125.

${ }^{7}$ Menssen reports that I claim that "women and men use different logics" (123 and passim), misleadingly implying that $I$ see the connection between sex and voice as a nucessary one. That she herself is so misled is evidenced by Part II of her paper where she attributes this thesis to Gilligan, Nona Lyons, and myself and offers as counter-evidence a catalogue of "great male thinkers" (p. 128 ff.) whose works display aspects of the feminine mode. Gilligan is clear that the different moral voices she distinguishes are marked by theme, and that the relationship of voice to sex is empirical and contingent, and further, the argument of her book is that the link between voice and sex is through the intermediate term, gender (In a Different Voice, p. 2 and passim). In addition, her chap. 6 explores the convergence of the two voices in individuals of both sexes. In my paper I note, following Gilligan, that the association between voice and sex is empirical (Op. cit., p. 3), that the logics of each voice are a function of gender socialization ( $p .3$ ), and that men and women can and do employ both styles of rationality (p.6).

"Carol Gilligan discusses and presents evidence for a "convergence ethic' in chap. 6 of In $a$ Different Voice.

${ }^{9}$ Lorde, Audre. "The Master's Tools will Dismantle the Master's House" in Sister Outsider (Freedom, Ca:: The Crossing Press), p. 112.

1) Nye, Andrea, Words of Power: A Feminist Reading of the History of Logic. (New York: Routledge), 1990, p.174.

"Jaggar, Alison M., "Love and Knowledge: Emotion in Feminist Epistemology", Gender/Body/Knowledge/Feminist Reconstructions of Being and Knowledge. Alison $M$. Jaggar and Susan R. Bordo (ed.), (New Brunswick: Rutgers Univ. Press), p. 154.

12 Nye, Op. cit., p. 175.

${ }^{13}$ Wittgenstein, Ludwig, Op. cit., sec. 108.

14 Jaggar, Alison M.. Feminist Politics and Human Nature (New Jersey: Rowman \& Allanheld), 1983.

${ }^{15}$ Of course, not all natural language (by which I mean very generally the language of everyday discourse) can serve this function. Primitive language-games, as well as those developed in resistance to oppression, would be a more likely source of alternatives than language-games structured by the assumptions and values of the oppressor which may also be played. willingly or unwillingly, naively or consciously, by the oppressed.

${ }^{16}$ Nye, Op. cit., p. 176.

${ }^{17}$ Parsons. Susan F., "Feminism and the Logic of Morality: A Consideration of Alternatives." in Ethics: A Feminist Reader. Elizabeth Frazer. et al (eds), (Oxford: Blackwell).1992, pp.404. 


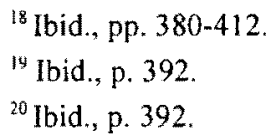

${ }^{21}$ Wittgenstein, Op. cit., sec. 93.

${ }^{22}$ It is, of course, well known that Wittgenstein's work in Philosophical Investigations is in reaction to the "grave mistakes" (Preface, $x$ ) contained in his earlier work on the universal logic, Tractatus Logico-Philosophicus (trans. by D.F. Pears \& B.F. McGuinness. London; Routledge \& Kegan Paul, 1961), in which he described just such an illusory crystalline structure.

${ }^{23}$ Ibid, sec. 97.

${ }^{24}$ Wittgenstein, Ludwig, Remarks on The Foundations of Mathematics, G.H. von Wight. R. Rhees and G.E.M. Anscombe (eds.), trans. by G.E.M. Anscombe, (Cambridge, Mass.: The MIT Press), 1975, Part I, sec. 8.

${ }^{25}$ Orr, Deborah Jane, Wittgenstein on Understanding Self and Others, unpublished Doctoral thesis, York University, July, 1985.

${ }^{26}$ Linda J. Nicholson makes some of the reasons for this need explicit in her "Women, Morality, and History" in An Ethic of Care: Feminist and Interdisciplinary Perspectives, Mary Jeanne Larrabee (ed.), (New York: Routledge), pp. 87-101.

${ }^{27}$ Lawrence A. Blum in "Gilligan and Kohlberg: Implications for Moral Theory", pp.49-68. makes this point as do Owen Flanagan and Kathryn Jackson in "Justice. Care. and Gender". pp. 69-84. Carol Stack's research with black return migrants to the rural southern U.S. reported in "The Culture of Gender: Women and Men of Color". pp. 108-111. leads to a similar conclusion, as does Nicholson, Op. cit. All papers are in Larrabee, Mary Jeanne (ed.) An Ethic of Care: Feminist and Interdisciplinary Perspectives.

${ }^{28}$ Gilligan, In a Different Voice, p. 2

${ }^{29}$ Gilligan, Ibid., p. 1.

${ }^{30}$ Gilligan, Ibid., p. 2.

31 Andrea Nye maintains (Feminist Theory and the Philosophies of Man. (New York: Routledge), 1988, pp. 215-216) that a very similar set of hierarchies in Aristotle's Politics (Chap. 3-13), which reflect the symbolic system and way of life of his era, have mulated over history to become some of the major organizational hierarchies our own cra: EuroAmerican/Third World; civilised/primitive; materialism/idealism and conscious/unconscious.

${ }^{32}$ Sherry Ortner discusses this relationship in her ground breaking paper "ls Female to Male as Nature Is to Culture?" in Michelle Z. Rosaldo and Louise Lamphere (eds.). Woman. (uture and Society (Stanford: Stanford Univ. Press), 1974, pp. 67-87.

${ }^{33}$ In their Thinking Critically About Research on Sex and Gender (New York: Harper Collins College Publishers) 1994. Paula J. Caplan and Jeremy B. Caplan argue that much of the 'scientific' research and reporting showing sex difference is fatally biased and misleadingly supports cultural assumptions of difference where little or none exists.

${ }^{34}$ Gilligan, In A Different Voice, Chap. 6.

35. Chodorow, Nancy, The Reproduction of Mothering: Psychoamalysis and the fociology of Gender (Berkeley: Univ, of California. Press) 1978, see especially Chap. 11.

${ }^{36}$ The work of Janet Lever (p. 9-10) cited in Gilligan, Op. cit., is supportive of this point. 
37 Benhabib, Seyla, "The Generalized and the Concrete Other: The Kohlberg-Gilligan Controversy and Feminist Theory", Feminism as Critique, Bentabib. Seyla and Drucilla Cornell (ed.), (Minneapolis: Univ. of Minnesota Press), 1987, 77 - 95.

${ }^{38}$ Wittgenstein, Ludwig, Philosophical Investigations, passim but especially sec. $240 \mathrm{ff}$.

${ }^{39}$ Bakan, David, The Duality of Human Existence (Boston: Beacon Press), 1966.

Jaggar, Alison M., Op, cit, pp. 145-171.

4! lbid., p. 155 .

42 Ibid. p. 155.

${ }^{43}$ Gilligan, In a Different Voice, p. 26.

${ }^{44}$ Kant, Immanuel, Fundamental Principles of the Metaphysic of Morals, trans. Thomas K. Abbott (Indianapolis: Bobbs-Merrill Ed. Pub.), 1949, p. 18.

${ }^{45}$ Rawls, John. A Theory of Justice (Cambridge, Mass.: Harvard Univ. Press), 1971. Chap. 24.

${ }^{46}$ Menssen, Op. cit., p. 125.

${ }^{47}$ Ibid., p. 126.

${ }^{48} \mathrm{Ibid}_{x,}$ p. 125.

${ }^{49}$ Ibid., p. 125.

50) Parson, Kathryn Pyne, "Nietzsche and Moral Change". Nietzsche: A Collection of Critical Essays, Robert Solomon (ed.), (Garden City, New York: Anchor Books), 1973, 169-193. She distinguishes four features of what she calls traditional ethics and what $I$ am calling. with reference to Kuhn, patriarchal normal ethics: (1) a focus on notions of obligation. (2) the centrality of moral principle. (3) the justification of principle by argument, and (4) the [deductive] justification of acts by principles (p. 169 and passim). This seems to me to capture the main features of what both Kohlberg and Gilligan understand by a justice ethic.

${ }^{5}$ Menssen, Op. cit., p. 125.

32 lbid., p. 125.

${ }^{53}$ Ibid., p. 124.

${ }^{54}$ She maintains that Gilligan has "pointed out" this "stupidity" (p. 124) but 1 fail to find either this language or attitude in In a Different loice.

${ }^{55}$ Ibid. p. 124-125.

${ }^{56}$ Gilligan, In a Different Voice, p. 31.

${ }^{57}$ Mullett, Op. cit.

\$8illigan, In a Different Voice, p. 73.

${ }^{59}$ Lenore Langsdorf, in her referee's report on this paper, has quite correctly pointed out the need to problematize Gilligan's contrast of "psychological logic of relationships" and "formal logic of fairness". In Langsdorf"s words what she calls "a "logic of the lifeworld"... isn't either 'formal' or "psychological"; it is rooted in empirical (embodied and sedimented) practices of relating to concrete others." I myself am anbivalent about "psychological logic of relationships" in that it helps to capture the dimension of relationship with concrete others which needs to be foregrounded in logic, but may do so at the expense of tempting one into psychologism or into ignoring the broader context of those relationships-the lifeworld-which 1 have attempted to point to throughout the paper and especially in my reliance in Wittgenstein's work. Clearly, this is a topic which needs much more attention than 1 am able to give it in this paper. 
${ }^{60}$ Wittgenstein, Ludwig, On Certainty, G.E.M. Anscombe and G.H. von Wright (eds.), (New York: Harper \& Row), 1969., sec. 56.

${ }^{61}$ Mullett, Op, cit., p. 33.

$\$ 2$ I suspect, although I will not pursue the point here, that intimacy and close personal relationship also lie at the heart of the care-like ethics detected by researchers who focus on other groups e.g., in Carol Stack's work, Op. cit.

${ }^{63}$ Ibid., p. 33.

${ }^{64}$ Ibid., p. 32.

${ }^{65}$ Wittgenstein, On Certainty, sec. 95.

${ }^{6 h}$ There would, of course, be a dichotomous world-picture functioning in Jake's response which I will not attempt to describe here. One of its most vivid articulations has been Hobbes' description of "man" in a state of nature.

${ }^{67}$ Mullett, Op. cit., p. 33.

${ }^{68}$ Grimshaw, Jean, Philosophy and Feminist Thinking, (Minneapolis: Univ. of Minnesota Press), 1986, p. 86.

${ }^{60}$ Mullett, Op. cit., p. 33.

${ }^{7}$ Gilligan, In a Different Voice, p. $85 \mathrm{ff}$.

${ }^{7}$ Mullett, Op. cit., p. 33

${ }^{72}$ Although his work is too centred in liberal individualism in its conception to be directly applicable to the practitioner of an ethic of care. John Kekes shows much insight in his discussion of moral depth and breadth and develops an interesting notion of moral idioms. See his "Moral Sensitivity", Philosophy, 59, 1984, 3-19.

${ }^{73}$ Mullett, Op. cit, p. 33.

${ }^{74}$ See Wittgenstein, On Certainty, sec. 7 and passim.

${ }^{75}$ Ibid., sec. 447 and passim.

${ }^{76}$ Although his discussion is essentialized, David Bakan explores the connection between ego style [gender] and culture in interesting and insightful ways and argues that agency [masculinity] unmitigated by communion [femininity] is "evil" in his The Duality of Human Existence.

${ }^{17}$ Gilligan, In a Different Voice, p. 28.

${ }^{78}$ Ibid., p. 26.

${ }^{70}$ Code, Lorraine, What Can She Know?: Feminist Theory and the Construction of Knowledge, (Ithaca: Cornell Univ. Press), 1991, p. 107.

80 Lawrence A. Blum, Op. cit., esp. pp. 53ff, disproves eight reductionist attempts to incorporate Gilligan's ethic of care into the justice ethic paradigm which he calls the "impartialist conception of morality".

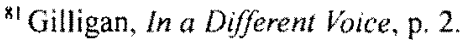

${ }^{2}$ Ibid., p. 167.

${ }^{83}$ Nicholson, Linda J., "Women. Morality, and History" in An Ethic of Care: Feminist and Interdisciplinary Perspectives.

"Warren, Karen, "Critical Thinking and Feminism", Informal Logic. X. 1. (Winter 1988), pp. $31-44$.

${ }^{85}$ Nye, Andrea, Words of Power, p. 178. 
${ }^{* 6}$ See fn. 15.

${ }^{87}$ Nye, Words of Power, p. 181.

${ }^{88}$ Menssen, Op. cit., p. 136.

${ }^{89}$ Nye, Words of Power, p. 180.

DEBORAH ORR DIVISION OF HUMANITIES, YORK UNIVERSITY NORTH YORK, ONT. M3J IP3 